\title{
STUDI PERBANDINGAN PEMASANGAN MATERIAL WATERPROOFING JENIS SELF ADHESIVE MEMBRANE DENGAN CRYSTALLINE
}

\author{
Ekka Kozaly $^{1}$ dan Arianti Sutandi ${ }^{2}$ \\ ${ }^{1}$ Program Studi Sarjana Teknik Sipil, Universitas Tarumanagara, Jl. Letjen S. Parman No.1 Jakarta \\ Email: ekkaakozaly@gmail.com: \\ ${ }^{2}$ Program Studi Sarjana Teknik Sipil, Universitas Tarumanagara, Jl. Letjen S. Parman No.1 Jakarta \\ Email: ari.sutandi@gmail.com
}

\begin{abstract}
ABSTRAK
Pekerjaan waterproofing pada suatu bangunan sangat penting terutama pada lantai basement. Dalam pekerjaan pemasangan waterproofing terdapat banyak jenis material waterproofing yang ditawarkan dengan harga dan durasi pekerjaan yang beragam. Dalam studi ini dibandingkan material dari segi harga dan durasi pekerjaan. Untuk perhitungan harga dihitung jumlah harga material terpasang. Untuk durasi pekerjaan dibandingkan luas daerah yang telah tertutupi waterproofing selama waktu pengamatan. Dua jenis waterproofing yang dibandingkan adalah jenis self adhesive membrane dan crystalline. Setelah ditentukan jenis waterproofing yang digunakan, agar suatu proyek berjalan tepat waktu maka perlu diperhitungkan tingkat produktivitas pekerjaannya. Pada analisis ini juga dibandingkan tingkat produktivitas pekerjaan pemasangan waterproofing pada kedua proyek dimana tiap waterproofing tersebut dipasang. Pengambilan sampel dilakukan dengan cara random activity sampel dan perhitungan produktivitas menggunakan metode work sampling dan metode labor utilization rate (LUR). Dari hasil perhitungan, untuk produktivitas dan efektivitas didapat nilai produktivitas proyek A tempat terpasangnya self adhesive membrane waterproofing sebesar 30,07 $\mathrm{m}^{2}$ /orang-hari dengan nilai LUR sebesar 88,18 \% dan total harga adalah sebesar Rp 550.000,00 per $\mathrm{m}^{2}$-hari. Sementara untuk crystalline waterproofing pada proyek B didapat hasil perhitungan produktivitas sebesar 40,39 $\mathrm{m}^{2}$ /orang-hari dengan nilai LUR sebesar 80,23\% dan total harga sebesar Rp 150.000,00. Luas daerah yang telah tertutupi waterproofing untuk proyek A dan B masing-masing seluas $7981,55 \mathrm{~m}^{2}$ dan $8707,5 \mathrm{~m}^{2}$.
\end{abstract}

Kata kunci : waterproofing, produktivitas, efektivitas, work sampling, labor utilization rate

\section{PENDAHULUAN}

Semakin meningkat dan cepatnya pembangunan khususnya di Jakarta ini, maka tentunya material-material yang dibutuhkan untuk pembangunan semakin banyak pula. Dalam setiap pembangunan terutama gedung-gedung bertingkat tinggi, biasanya akan dibuat basement sebagai tempat parkir dikarenakan lahan yang terbatas namun kebutuhan akan tempat parkir sangat besar. Salah satu komponen penting dalam pembuatan basement adalah adanya pekerjaan waterproofing atau pekerjaan pembuatan lapisan kedap air yang membantu menahan agar air dari dalam tanah tidak menekan dan masuk ke dalam bangunan dan menyebabkan kerusakan. Ada bermacam-macam jenis waterproofing yang digunakan pada basement. Namun yang akan dibahas pada studi kali ini adalah self adhesive membrane waterproofing dan crystalline waterproofing.

Akan tetapi, jika material waterproofing yang digunakan memiliki kualitas terbaik bukan berarti proyek akan berarti proyek akan berjalan lancar dengan cepat tanpa ada hambatan dan kendala. Suatu keberhasilan proyek konstruksi secara keseluruhan tergantung dari keberhasilan setiap pekerjaan yang ada dalam proyek tersebut, sedangkan salah satu faktor yang mempengaruhi keberhasilan suatu pekerjaan di proyek adalah produktivitas tenaga kerjanya. Tenaga kerja merupakan salah satu aspek yang sangat menentukan keberhasilan dalam suatu implementasi proyek, yang dituntut untuk bekerja secara efisien, yaitu dapat bekerja efektif sesuai dengan jumlah jam kerja yang ada dan dapat menghasilkan volume pekerjaan sesuai dengan uraian pekerjaan yang ada. Sehingga diharapkan dengan hal tersebut dapat menunjang kemajuan serta mendorong kelancaran proyek baik untuk tiap pekerjaan maupun proyek secara keseluruhan.

Dari penjelasan diatas akan dilakukan penelitian mengenai dua jenis waterproofing, self adhesive membrane dan crystalline, mana yang lebih baik jika dilihat dari segi harga dan waktu pemasangan. Serta menghitung produktivitas tenaga kerja berdasarkan tingkat efektifitas dalam bekerja (labour utilization rate) dalam menyelesaikan pekerjaan pemasangan waterproofing agar suatu proyek dapat dapat berjalan secara efektif dengan memaksimalkan kinerja tenaga kerjanya. 


\section{Rumusan Masalah}

Rumusan masalah yang akan dibahas antara lain :

1. Apa saja jenis waterproofing yang umumnya digunakan pada pekerjaan basement?

2. Apakah metode pelaksanaan yang dilakukan di lapangan sesuai dengan standar operasional yang berlaku?

3. Bagaimana tingkat produktivitas tenaga kerja pada pekerjaan waterproofing pada masing-masing proyek?

\section{Maksud dan Tujuan Penelitian}

Maksud penulisan ini adalah untuk studi penerapan tentang berbagai jenis waterproofing yang digunakan dalam basement dan mengetahui tingkat produktivitas suatu proyek dilihat dari pekerjaan waterproofing.

Tujuan penulisan ini adalah untuk mengetahui jenis-jenis waterproofing yang dapat digunakan pada basement dan membandingkan dua jenis antara jenis self adhesive membrane dan crystalline ditinjau dari segi biaya dan produktivitas tenaga kerja dari masing-masing proyek.

\section{Ruang Lingkup dan Batasan Masalah}

Ruang lingkup dalam penulisan ini adalah pemasangan waterproofing pada basement.

Batasan masalah dalam penulisan ini adalah :

1. Pekerjaan waterproofing, yakni metode pelaksanaan pemasangan waterproofing di lapangan dan spesifikasi teknis dari waterproofing yang digunakan pada basement.

2. Waktu pengamatan dalam sehari dibagi dalam 2 sesi, pukul $08.00-12.00$ dan pukul $13.00-17.00$.

\section{LANDASAN TEORI}

\section{Produktivitas}

Produktivitas merupakan perbandingan total output berupa barang maupun jasa pada waktu tertentu dibagi dengan total input-nya yang antara lain bisa berupa: man-power, manajemen, material, modal, dan mesin yang dimiliki (Olomolaiye, 1998). Berpijak dari beberapa definisi di atas, maka jelaslah bahwa secara singkat, produktivitas ini dapat diartikan sebagai output dibagi dengan input. Akan tetapi, dari pengertian ini lahirlah suatu masalah bahwa meskipun cukup mudah untuk mendefinisikan input yang diperlukan untuk melakukan suatu kegiatan produksi dalam satuan kuantiatif yang nantinya mudah untuk dianalisis lebih lanjut (biasa dinyatakan dalam satuan Rupiah, Orang-Hari, dll.), namun tidak demikian dengan output yang dihasilkan. Seluruh jenis proyek pada pekerjaan konstruksi tergolong unik (tidak bisa disamakan antar jenis proyek, misalnya: proyek jalan dengan gedung bertingkat tinggi) dan tidak repetitif. Hal inilah yang kemudian mempersulit dalam penentuan suatu ukuran standar yang bisa digunakan untuk mendefinisikan output tersebut hingga akhirnya diputuskan untuk membagi aktivitasaktivitas yang akan diamati menjadi aktivitas yang lebih sederhana dan bisa diamati secara kuantitatif. Contohnya: produktivitas pekerjaan pemasangan waterproofing pada basement. Beberapa metode yang biasanya digunakan untuk produktivitas, antara lain: time study dan random activity sampling, yang meliputi field ratings dan productivity ratings (Pilcher, 1992).

\section{Work Sampling}

Pengukuran produktivitas tenaga kerja sulit dilakukan secara akurat, memerlukan tenaga dan biaya yang besar (Olomolaiye et al, 1998). Untuk mencapai nilai produktivitas yang diharapkan, perencanaan durasi harus dilakukan dengan mempertimbangkan jumlah kelompok kerja yang ada sehingga perencanaan yang dihasilkan dapat sesuai dengan kemampuan tenaga kerja yang ada. Seperti yang sudah dibahas di atas bahwa pengukuran produktivitas tenaga kerja sulit dilakukan secara akurat karena sifat dasar dari pekerja tidak stabil dalam pelaksanaan konstruksi (Olomolaiye et al, 1998), maka pengukuran produktivitas tenaga kerja dilakukan dengan cara pendekatan, yaitu dengan metode work sampling. Work sampling merupakan suatu teknik pengukuran dan analisis produktivitas dengan mengaplikasikan prinsip-prinsip statistik untuk segala aktivitas.

Baik aktivitas yang efektif maupun tidak, dengan cara mengambil sampel secara acak (namun harus dapat mewakili seluruh populasi yang ada) dan kemudian menganalisisnya secara lebih lanjut (Pilcher, 1992). Sampel secara acak yang dimaksud di sini adalah bahwa setiap individu atau bagian dari populasi yang akan kita amati harus memiliki kemungkinan yang sama besar untuk kita ambil sebagai sampel, tanpa adanya pembedaan atau penekanan pada beberapa individu tertentu, seluruh elemen dipandang memiliki nilai yang sama. Keuntungan terbesar dari pemilihan metode work sampling ini adalah adanya kemungkinan untuk mengambil data atau mempelajari banyak orang 
sekaligus dalam satu penelitian. Dalam pengerjaan penelitian dengan menggunakan work sampling ini, ada beberapa metode yang biasanya diterapkan atau diaplikasikan untuk tahap pengumpulan datanya, antara lain: dengan observasi langsung di lapangan, dengan wawancara langsung dengan pihak-pihak yang berkaitan dengan penelitian ini dan kepada responden yang dinilai cukup mumpuni untuk memberikan keterangan yang akurat dan dapat dipertanggungjawabkan. Work sampling memiliki prinsip-prinsip untuk digunakan, prinsip-prinsip dari work sampling adalah (Oglesby et al., 1989 dalam Wibowo \& Prasetya, 2004):

1. Sampel yang diamati tidak boleh kurang dari 50 pengamatan, dapat dihitung dengan rumus di atas. Data-data yang dikumpulkan dari pengamatan harus sedekat mungkin dengan kenyataan yang ada, artinya apabila sampel yang diambil semakin banyak, maka hasil pengamatan semakin akurat.

2. Sampel terkumpul dari bermacam-macam bagian siklus tenaga kerja untuk memastikan setiap unit mempunyai kesempatan yang sama untuk terpilih.

3. Di kelompok besar manapun, sebuah sampel diambil secara random (acak) yang akan mewakili sebagian atau seluruh karekteristik dari kelompok tersebut.

Yang dimaksud dengan random (acak) adalah (Kaming, 1997):

a. Setiap pekerja mempunyai kemungkinan yang sama untuk terpilih dan terinspeksi.

b. Kondisi tiap pekerja bebeda-beda, tidak boleh disamakan dengan pekerja yang lain.

c. Nilai sebuah elemen terbentuk saat pertama kali dilihat. Pengamatan tidak boleh dilakukan dengan menebak pekerjaan yang sedang dilakukan pekerja itu, sudah selesai dilakukan, ataupun yang akan dilakukan.

d. Dasar karekteristik dari situasi sampling tidak boleh diubah selama pengamatan berlangsung.

e. Pengambilan data dilakukan dengan waktu yang bervariasi (acak).

4. Untuk menghindari prasangka, pencatatan harus dilakukan secara cepat (instan) tanpa ragu-ragu seperti apa yang dilihat pertama kali.

5. Semua yang berkaitan dengan survei harus diamati, setidaknya $75 \%$ dari pekerja harus masuk dalam sampel untuk mendapatkan hasil yang dapat dipertanggungjawabkan.

6. Tidak boleh ada pencatatan yang ganda. Maksudnya, satu pekerja tidak boleh dicatat sampai dua kali atau lebih pada waktu yang sama.

Beberapa aktivitas yang perlu dipersiapkan atau dikerjakan terlebih dahulu sebelum melaksanakan penelitian dengan metode work sampling ini, antara lain: mendefinisikan terlebih dahulu aktivitas apa saja yang sekiranya efektif dan tidak, menyiapkan suatu lembar kerja atau formulir yang seragam untuk setiap jenis aktivitas yang sama untuk mempermudah pengambilan data,

menetapkan confidence limit dan limit of error yang diharapkan dari penelitian ini. Dalam praktik di dunia konstruksi pada umumnya, nilai $95 \%$ confidence limit dengan $\pm 5 \%$ limit of error dirasa sudah cukup baik untuk memberikan hasil penelitian yang akurat dalam usaha analisis pengukuran produktivitas suatu aktivitas (dan beserta upaya peningkatannya di kemudian hari).

\section{Labor Utilization Rate}

Labor utilization rate (LUR) adalah persentase yang didapat dari penjumlahan effective work ditambahkan dengan $1 / 4$ essential contributory work, kemudian membagi penjumlahan tersebut dengan total pengamatan (Olomolaiye et al., 1998 dalam Wibowo \& Prasetya, 2004).

$$
\text { LUR }=\frac{\text { Effective Work }+1 / 4 \text { Essential } \text { Contributory Work }}{\text { Total }}
$$

Dalam usaha pengukuran produktivitas, salah satu masukan atau input yang paling banyak digunakan sebagai pembanding dari hasil aktivitas yang dilaksanakan (output) adalah variabel waktu. Akan tetapi, berdasarkan kenyataan yang ada di lapangan, tidak semua waktu yang diperlukan untuk menghasilkan suatu output seluruhnya bisa berkontribusi secara langsung terhadap hasil yang diperoleh. Ada beberapa waktu yang terbuang untuk proses para pekerja berpindah tempat, mengaduk plesteran dalam aktivitas pemasangan dinding bata, dll. Aktivitasaktivitas ini tentu mengakibatkan turunnya produktivitas yang kita ukur tetapi juga tidak bisa dipisahkan dari aktivitas yang sedang dikerjakan tersebut. Adapun kelemahan apabila menggunakan metode ini salah satunya adalah tidak diketahuinya faktor-faktor penyebab rendahnya produktivitas pekerja. Aktivitas-aktivitas dalam suatu proyek konstruksi terbagi menjadi: 
1. Productive/Effective activities merupakan aktivitas yang berkontribusi langsung terhadap keluaran yang diharapkan dari suatu aktivitas, contohnya: menuang beton segar pada tempat yang akan dicor, memasang bata merah untuk pasangan dinding, dan lain-lain.

2. Contributory activities merupakan aktivitas-aktivitas yang tidak langsung memberikan dampak pada keluaran yang diharapkan pada proyek konstruksi, akan tetapi seringkali krusial atau wajib dilakukan untuk mendukung productive activities yang akan dilakukan, misalnya: membaca gambar kerja yang akan dilaksanakan, menerima instruksi atau perintah dari mandor, dsb.

3. Unproductive/Ineffective activities merupakan aktivitas menganggur, menunggu atau aktivitas lain yang sama sekali tidak memberikan sumbangan positif bagi kemajuan progress proyek misalnya: merokok pada saat jam kerja, berbincang-bincang mengenai hal yang tidak ada hubungannya dengan tugas yang harus diselesaikan, dll (Olomolaiye et al, 1998).

\section{METODOLOGI PENELITIAN}

\section{Jenis Sumber Data}

Dalam penelitian ini, data yang digunakan, yaitu berupa 476 data objek yang diperoleh dari hasil observasi aktivitas tenaga kerja secara langsung di proyek A dan B selama dua bulan masa pengamatan dan juga hasil wawancara singkat dengan beberapa pekerja aktif proyek pada saat pengamatan dilakukan. Responden wawancara adalah pekerja, mandor, pengawas lapangan, dan kontraktor yang ikut berkontribusi baik dalam pelaksanaan maupun pengawasan pekerjaan pada hari tersebut.

\section{Teknik Penarikan Sampel}

Teknik pengambilan sampel yang digunakan dalam penelitian ini adalah random activity sampling, yaitu melakukan pengukuran aktivitas dalam setiap fase pekerjaan baik aktif maupun pasif dengan mengkaji sampel berjumlah sedikit namun dapat mewakili. Wawancara dilakukan pada pekerja yang pada saat pengamatan berada di lapangan.

\section{Observasi dan Pengambilan Data}

Sumber data adalah proyek konstruksi bangunan proyek A dan B yang sedang berjalan. Pengambilan data dilakukan pada basement. Pengambilan data berjalan selama dua bulan.

\section{Teknik Pengumpulan Data}

Metode pengumpulan data yang digunakan dalam penelitian ini adalah observasi dan pencatatan data secara langsung pada form work sampling yang telah dibuat untuk dijadikan pedoman dalam melakukan wawancara singkat dengan pekerja aktif yang berada di lapangan sebagai data primer.

\section{Teknik Analisis Data}

Data yang sudah diperoleh dari observasi pada masing-masing proyek A dan B langsung diolah untuk menemukan nilai produktivitas dan nilai LUR setiap pekerjaan yang selanjutnya akan dibandingkan satu sama lain.

\section{HASIL DAN PEMBAHASAN}

\section{Perbedaan Aplikasi Crystalline Waterproofing di Lapangan dengan SOP}

- Pada saat pencampuran admixture juga ditemukan campuran tidak sesuai dengan persentase yang dianjurkan oleh produsen. Saat ditanyakan kepada aplikator dikatakan bahwa telah dikomunikasikan dengan yang berwenang bahwa kejadian di lapangan terjadi seperti itu dan dikatakan bahwa perbedaan pada saat aplikasi di lapangan tersebut masih dapat ditolerir.

- Di awal sebelum melakukan pemasangan waterproofing daerah permukaan yang akan dikerjakan tidak dibasahi oleh air. Sementara pada SOP dikatakan bahwa pada pemasangan crystalline waterproofing harus pada permukaan jenuh karena campuran pada admixture terkandung air yang bisa terserap permukaan beton.

- Pada Rabu, 25 April 2018 saat melakukan pengamatan, terdapat beberapa hari dimana terjadi hujan pada saat aplikasi waterproofing. Dan ada beberapa daerah di basement yang berada di area terbuka. Sehingga membuat material waterproofing yang sebelumnya sudah terpasang tersapu air. Akibatnya pada daerah terbuka tersebut 
harus dilakukan kembali pekerjaan waterproofing agar bisa didapat lapisan waterproof yang bisa menahan air agar tidak tembus.

- Pada saat pekerjaan pengecatan atau coating menggunakan kuas ke permukaan beton lantai kerja basement tidak sesuai SOP. Pada saat pengamatan di lapangan ditemukan bahwa khususnya pada daerah dekat kolom, lantai kerja basement dilapisi lebih dari sekali, sedangkan pada SOP cukup sekali saja.

\section{Perbedaan Aplikasi Self Adhesvie Membrane Waterproofing di Lapangan dengan SOP}

- Selama pengamatan terdapat beberapa daerah yang permukaannya masih basah, sementara pada SOP tertulis bahwa pada saat pemasangan daerah permukaan yang akan dipasang harus bersih dan kering.

- Pada tanggal 2 Mei 2018, saat pengamatan di lapangan didapati bahwa ada beberapa daerah yang kurang merata tertutupi waterproofing. Sebagian dilakukan dua kali aplikasi waterproofing karena sobek terkena tulangan atau peralatan proyek yang tajam.

- Pada tanggal 25 April 2018, saat pengamatan di lapangan didapati bahwa daerah-daerah dengan medan sulit seperti daerah sekitar kingpost, waterproofing yang berbentuk gulungan dibuka kemudian dipotong menjadi lembaran-lembaran dengan luas sesuai dengan yang dibutuhkan baru kemudian direkatkan dengan tape anti air. Sementara pada SOP disebutkan bahwa self adhesive membrane mempunyai perekat sendiri yang khusus untuk merekatkannya dengan sesama membran dan dengan beton permukaan basement.

- Waterproofing memiliki fungsi untuk menutupi lapisan permukaan beton lantai kerja pada basement agar menjadi kedap air. Namun selama pengamatan di lapangan hingga selesai pengamatan didapati beberapa daerah tumpukan self adhesive membrane yang teletak di lantai. Akibatnya tumpukan waterproofing tersebut digunakan sebagai alas duduk oleh para tukang yang beristirahat sehingga merusak struktur waterproofing tersebut.

- Para pekerja kurang hati-hati saat memindahkan, membuka, dan memasang waterproofing membuat beberapa waterproofing sobek sehingga tidak bisa digunakan.

- Terdapat beberapa daerah dimana waterproofing tidak secara rapi terpasang dengan baik. Biasanya daerahdaerah tersebut memiliki beda ketinggian, contohnya daerah dekat dinding atau kingpost. Kerutan tersebut terjadi dikarenakan beberapa alasan seperti permukaan belum bersih namun langsung dipasang waterproofing, ataupun kurang rapi saat pemasangan sehingga timbul kerutan-kerutan dan membuat permukaan menjadi tidak rata.

- Banyak terdapat waterproofing yang sudah diturunkan ke lapangan untuk dipasang, namun daerah yang akan dipasang belum siap. Sehingga waterproofing dibiarkan begitu saja di lantai dan sebagian besar berubah fungsi menjadi tempat duduk, bersandar, atau tempat beristirahat para tukang.

\section{Perhitungan Produktivitas}

Analisis dari produktivitas pekerjaan waterproofing dilakukan dengan melakukan rata-rata dari seluruh rekapitulasi data produktivitas tenaga kerja.

Tabel 1 Perhitungan Produktivitas Tenaga Kerja Proyek A dan B

\begin{tabular}{|c|c|c|c|c|c|c|c|c|}
\hline \multirow[b]{2}{*}{ No. } & \multicolumn{4}{|c|}{$\mathrm{A}$} & \multicolumn{4}{|c|}{$\mathrm{B}$} \\
\hline & $\begin{array}{c}\text { Jumlah } \\
\text { Roll } \\
\text { yang } \\
\text { Digunakan }\end{array}$ & $\begin{array}{c}\text { Luas Area } \\
\text { yang } \\
\text { Dikerjakan } \\
\left(\mathrm{m}^{2}\right)\end{array}$ & $\begin{array}{l}\text { Jumlah } \\
\text { Pekerja } \\
\text { (orang) }\end{array}$ & $\begin{array}{l}\text { Produktivitas } \\
\text { (m2/orang/hari) }\end{array}$ & $\begin{array}{c}\text { Jumlah Sak } \\
\text { yang } \\
\text { Digunakan }\end{array}$ & $\begin{array}{l}\text { Luas Area } \\
\text { yang } \\
\text { Dikerjakan } \\
\left(\mathrm{m}^{2}\right)\end{array}$ & $\begin{array}{l}\text { Jumlah } \\
\text { Pekerja } \\
\text { (orang) }\end{array}$ & $\begin{array}{l}\text { Produktivitas } \\
\text { (m2/orang/hari) }\end{array}$ \\
\hline 1 & 4 & 328.01 & 10 & 32.80 & $\frac{7}{7}$ & 283.50 & 8 & 35.44 \\
\hline 2 & $\begin{array}{l}4 \\
6\end{array}$ & 364.46 & 10 & 36.45 & $\begin{array}{l}\frac{1}{7} \\
\end{array}$ & 303.75 & 8 & 37.97 \\
\hline 3 & $\begin{array}{l}3 \\
4\end{array}$ & 255.12 & 10 & 25.51 & $\begin{array}{l}8 \\
8\end{array}$ & 324.00 & 8 & 40.50 \\
\hline 4 & $\begin{array}{l}4 \\
6\end{array}$ & 364.46 & 10 & 36.45 & $\begin{array}{l}9 \\
8 \\
\end{array}$ & 344.25 & 8 & 43.03 \\
\hline 5 & $\begin{array}{l}2 \\
4 \\
\end{array}$ & 218.67 & 10 & 21.87 & $\begin{array}{l}5 \\
5\end{array}$ & 202.50 & 8 & 25.31 \\
\hline 6 & $\frac{3}{6}$ & 328.01 & 10 & 32.80 & $\begin{array}{l}7 \\
6\end{array}$ & 263.25 & 8 & 32.91 \\
\hline 7 & $\begin{array}{l}4 \\
4 \\
\end{array}$ & 291.56 & 9 & 32.40 & $\begin{array}{l}7 \\
8 \\
\end{array}$ & 303.75 & 8 & 37.97 \\
\hline 8 & $\begin{array}{l}4 \\
5 \\
\end{array}$ & 328.01 & 9 & 36.45 & $\begin{array}{l}9 \\
9 \\
\end{array}$ & 364.50 & 8 & 45.56 \\
\hline 9 & $\begin{array}{l}5 \\
5\end{array}$ & 364.46 & 9 & 40.50 & $\begin{array}{l}7 \\
8 \\
\end{array}$ & 303.75 & 8 & 37.97 \\
\hline 10 & $\frac{5}{4}$ & 328.01 & 9 & 36.45 & $\frac{4}{5}$ & 182.25 & 8 & 22.78 \\
\hline
\end{tabular}


Tabel 1 Perhitungan Produktivitas Tenaga Kerja Proyek A dan B (Lanjutan)

\begin{tabular}{|c|c|c|c|c|c|c|c|c|}
\hline \multirow[b]{2}{*}{ No. } & \multicolumn{4}{|c|}{$\mathrm{A}$} & \multicolumn{4}{|c|}{ B } \\
\hline & $\begin{array}{c}\text { Jumlah } \\
\text { Roll } \\
\text { yang } \\
\text { Digunakan }\end{array}$ & $\begin{array}{c}\text { Luas Area } \\
\text { yang } \\
\text { Dikerjakan } \\
\left(\mathrm{m}^{2}\right)\end{array}$ & $\begin{array}{l}\text { Jumlah } \\
\text { Pekerja } \\
\text { (orang) }\end{array}$ & $\begin{array}{l}\text { Produktivitas } \\
\text { (m2/orang/hari) }\end{array}$ & $\begin{array}{c}\text { Jumlah Sak } \\
\text { yang } \\
\text { Digunakan }\end{array}$ & $\begin{array}{c}\text { Luas Area } \\
\text { yang } \\
\text { Dikerjakan } \\
\left(\mathrm{m}^{2}\right)\end{array}$ & $\begin{array}{l}\text { Jumlah } \\
\text { Pekerja } \\
\text { (orang) }\end{array}$ & $\begin{array}{l}\text { Produktivitas } \\
\text { (m2/orang/hari) }\end{array}$ \\
\hline \multirow{2}{*}{11} & 2 & \multirow{2}{*}{145.78} & \multirow{2}{*}{6} & \multirow{2}{*}{24.30} & 10 & \multirow{2}{*}{324.00} & \multirow{2}{*}{8} & \multirow{2}{*}{40.50} \\
\hline & 2 & & & & 6 & & & \\
\hline \multirow{2}{*}{12} & 2 & \multirow{2}{*}{109.34} & \multirow{2}{*}{6} & \multirow{2}{*}{18.22} & 8 & \multirow{2}{*}{324.00} & \multirow{2}{*}{8} & \multirow{2}{*}{40.50} \\
\hline & 1 & & & & 8 & & & \\
\hline \multirow{2}{*}{13} & 2 & \multirow{2}{*}{109.34} & \multirow{2}{*}{4} & \multirow{2}{*}{27.33} & 7 & \multirow{2}{*}{283.50} & \multirow{2}{*}{8} & \multirow{2}{*}{35.44} \\
\hline & 1 & & & & 7 & & & \\
\hline 14 & 1 & 7289 & 4 & 1822 & 9 & 324.00 & 8 & 4050 \\
\hline 14 & 1 & 12.09 & 4 & 18.22 & 7 & 524.00 & 0 & 40.50 \\
\hline 15 & 1 & 72.89 & 4 & 18.22 & 6 & 222.75 & 8 & 27.84 \\
\hline & $\frac{1}{6}$ & & 10 & & $\frac{5}{9}$ & 225.10 & & \\
\hline 16 & 5 & 400.90 & 10 & 40.09 & 9 & 364.50 & 8 & 45.56 \\
\hline & 5 & 364.46 & 10 & 36.45 & 9 & 364.50 & 8 & 45.56 \\
\hline 17 & 5 & 504.40 & 10 & 50.43 & 9 & 504.50 & 0 & \\
\hline & 4 & & & & 7 & 263.25 & 8 & 32.91 \\
\hline 18 & 6 & 364.40 & 10 & 30.45 & 6 & 205.25 & 0 & 52.91 \\
\hline 19 & 5 & 328.01 & 10 & 32.80 & 6 & 243.00 & 8 & 30.38 \\
\hline & 4 & & & & 6 & & & \\
\hline 20 & 3 & 218.67 & 10 & 21.87 & 4 & 162.00 & 8 & 20.25 \\
\hline 20 & 3 & 210.01 & 10 & 21.01 & 4 & & & \\
\hline 21 & 5 & 364.46 & 12 & 3037 & 8 & 32400 & 6 & 54.00 \\
\hline 21 & 5 & 504.40 & 12 & 50.51 & 8 & 324.00 & 0 & 54.00 \\
\hline 22 & 4 & 437.35 & 12 & 36.45 & 7 & 303.75 & 6 & 50.63 \\
\hline 22 & 8 & 431.35 & 12 & 30.45 & 8 & 303.15 & 0 & 50.05 \\
\hline & 6 & & & & 6 & 283.50 & 6 & 47.25 \\
\hline 23 & 6 & $43 / .35$ & 12 & 36.45 & 8 & 205.50 & 0 & 41.25 \\
\hline 24 & 5 & 400.90 & 12 & 33.41 & 7 & 283.50 & 6 & 47.25 \\
\hline 24 & 6 & 400.90 & & & 7 & & & \\
\hline 25 & 4 & 255.12 & 12 & 21.26 & 4 & 182.25 & 6 & 30.38 \\
\hline $2 J$ & 3 & & 12 & & 5 & & & \\
\hline 26 & 4 & 291.56 & 10 & 29.16 & 9 & 364.50 & 6 & 60.75 \\
\hline 20 & 4 & 291.50 & 10 & 29.10 & 9 & & & \\
\hline 27 & 2 & 109.34 & 4 & 27.33 & 7 & 344.25 & 6 & 57.38 \\
\hline & 1 & 109.04 & & 21.03 & 10 & & & \\
\hline 28 & 2 & 145.78 & 4 & 36.45 & 7 & 303.75 & 6 & 50.63 \\
\hline 20 & 2 & & 4 & $50.4 J$ & 8 & & & \\
\hline 29 & 2 & 109.34 & 4 & 27.33 & 9 & 344.25 & 6 & 57.38 \\
\hline 25 & 1 & & T & 21.03 & 8 & & 0 & \\
\hline 30 & 1 & 72.89 & 4 & 18.22 & 6 & 222.75 & 6 & 37.13 \\
\hline 30 & 1 & 12.09 & 4 & 10.22 & 5 & 222.15 & 0 & Ji.1J \\
\hline & & a-rata & & 29.64 & & Rata-rata & & 49.28 \\
\hline
\end{tabular}

\section{Perhitungan LUR}

Perhitungan LUR untuk pekerjaan waterproofing dilakukan dengan melakukan rekapitulasi data secara keseluruhan terlebih dahulu. Jumlah pekerjaan effective, contributory, ineffective, dijumlahkan menurut klasifikasinya. Kemudian total nilai setiap perkerjaan digunakan untuk perhitungan LUR

Tabel 2 Perhitungan Labor Utilization Rate Proyek A dan B

\begin{tabular}{|c|c|c|c|c|c|c|c|c|}
\hline No. & $\begin{array}{c}\text { Jumlah } \\
\text { Pekerja }\end{array}$ & Effective & Contribury & Ineffective & $\begin{array}{c}\text { Jumlah } \\
\text { Pekerja }\end{array}$ & Effective & Contribury & Ineffective \\
\hline 1 & 10 & 10 & 0 & 0 & 8 & 8 & 0 & 0 \\
\hline 2 & 10 & 9 & 1 & 0 & 8 & 8 & 0 & 0 \\
\hline 3 & 10 & 9 & 0 & 1 & 8 & 7 & 0 & 1 \\
\hline 4 & 10 & 8 & 2 & 0 & 8 & 7 & 1 & 1 \\
\hline 5 & 10 & 8 & 2 & 0 & 8 & 7 & 1 & 0 \\
\hline 6 & 10 & 8 & 2 & 0 & 8 & 5 & 3 & 0 \\
\hline 7 & 9 & 9 & 0 & 0 & 8 & 5 & 3 & 0 \\
\hline 8 & 9 & 9 & 1 & 8 & & 0 \\
\hline
\end{tabular}


Tabel 2 Perhitungan Labor Utilization Rate Proyek A dan B (Lanjutan)

\begin{tabular}{|c|c|c|c|c|c|c|c|c|}
\hline No. & $\begin{array}{l}\text { Jumlah } \\
\text { Pekerja }\end{array}$ & Effective & Contribury & Ineffective & $\begin{array}{l}\text { Jumlah } \\
\text { Pekerja }\end{array}$ & Effective & Contribury & Ineffective \\
\hline 9 & 9 & 8 & 1 & 0 & 8 & 6 & 2 & 0 \\
\hline 10 & 9 & 7 & 1 & 1 & 8 & 6 & 1 & 1 \\
\hline 11 & 6 & 6 & 0 & 0 & 8 & 6 & 2 & 0 \\
\hline 12 & 6 & 5 & 0 & 1 & 8 & 7 & 1 & 0 \\
\hline 13 & 4 & 2 & 2 & 0 & 8 & 7 & 0 & 1 \\
\hline 14 & 4 & 2 & 1 & 1 & 8 & 6 & 1 & 1 \\
\hline 16 & 10 & 8 & 1 & 1 & 8 & 8 & 0 & 0 \\
\hline 17 & 10 & 9 & 0 & 1 & 8 & 6 & 1 & 1 \\
\hline 18 & 10 & 10 & 0 & 0 & 8 & 7 & 1 & 0 \\
\hline 19 & 10 & 10 & 0 & 0 & 8 & 8 & 0 & 0 \\
\hline 20 & 10 & 9 & 1 & 0 & 8 & 6 & 1 & 1 \\
\hline 21 & 12 & 10 & 2 & 0 & 6 & 5 & 0 & 1 \\
\hline 22 & 12 & 10 & 1 & 1 & 6 & 4 & 1 & 1 \\
\hline 23 & 12 & 10 & 2 & 0 & 6 & 5 & 1 & 0 \\
\hline 24 & 12 & 10 & 2 & 0 & 6 & 4 & 2 & 0 \\
\hline 25 & 12 & 11 & 1 & 0 & 6 & 4 & 2 & 0 \\
\hline 26 & 10 & 8 & 1 & 1 & 6 & 4 & 1 & 1 \\
\hline 27 & 4 & 4 & 0 & 0 & 6 & 4 & 1 & 1 \\
\hline 28 & 4 & 4 & 0 & 0 & 6 & 2 & 2 & 2 \\
\hline 29 & 4 & 3 & 1 & 0 & 6 & 2 & 2 & 2 \\
\hline 30 & 4 & 2 & 1 & 1 & 6 & 2 & 2 & 2 \\
\hline
\end{tabular}

\section{Harga}

Pada proyek A dan proyek B, material dan peralatan yang dibutuhkan selama pekerjaan waterproofing untuk masing-masing proyek antara lain sebagai berikut :

Material waterproofing yang digunakan :

- Preprufe 300R Plus ex GRACE (proyek A) harga terpasang : Rp 550.000,00 / $\mathrm{m}^{2}$

- $\quad$ Sika WT-200P (proyek B) harga terpasang : Rp $150.000,00 / \mathrm{m}^{2}$

\section{Analisis dan Pembahasan}

Dari data hasil pengamatan dilakukan perhitungan produktivitas pekerjaan pemasangan waterproofing jenis self adhesive membrane dan crystalline pada proyek A dan B. Setelah didapat hasil perhitungan dilakukan analisis dan pembahasan mengenai hasil perhitungan yang didapat.

Tabel 3 Perbandingan Self Adhesive Membrane dan Crystalline

\begin{tabular}{|c|c|c|c|}
\cline { 2 - 4 } \multicolumn{1}{c|}{} & $\begin{array}{c}\text { Produktivitas } \\
\left(\mathrm{m}^{2} / \text { orang-hari }\right)\end{array}$ & LUR $(\%)$ & $\begin{array}{c}\text { Luas yang Telah } \\
\text { Dikerjakan }\left(\mathrm{m}^{2}\right)\end{array}$ \\
\hline $\begin{array}{c}\text { Proyek A } \\
\text { (self adhesive } \\
\text { membrane })\end{array}$ & 30,07 & 88,18 & 7981.55 \\
\hline $\begin{array}{c}\text { Proyek B } \\
\text { (crystalline })\end{array}$ & 40,39 & 80,23 & 8707.5 \\
\hline
\end{tabular}


1. Dari perhitungan produktivitas pekerjaan waterproofing didapatkan hasil produktivitas proyek A sebesar $30,07 \mathrm{~m}^{2}$ orang-hari lebih kecil daripada produktivitas proyek B yaitu sebesar 40,39 $\mathrm{m}^{2}$ orang-hari.

2. Dari hasil perhitungan LUR pada kedua proyek, didapat nilai LUR dari masing-masing proyek, Proyek A sebesar 88,18\% dan Proyek B sebesar 80,23\%. Dari hasil perhitungan LUR dapat disimpulkan bahwa pekerjaan waterproofing yang dilakukan pada kedua proyek tersebut efektif (diatas $50 \%$ ).

3. Pada tabel 4.8 terlihat bahwa produktivitas pemasangan waterproofing di proyek A lebih kecil daripada produktivitas pada proyek B. Tetapi nilai LUR untuk pemasangan waterproofing proyek A lebih besar dari LUR proyek B. Hal ini memperlihatkan bahwa produktivitas lebih besar tidak selalu menunjukkan bahwa pekerjaan tersebut dilakukan dengan lebih efektif. Pada studi lapangan pemasangan waterproofing di proyek A dan proyek B terlihat bahwa jumlah tenaga kerja di proyek B pada beberapa waktu pengamatan lebih banyak daripada yang dibutuhkan.

4. Waktu pemasangan waterproofing jenis crystalline pada proyek B lebih cepat dari jenis self adhesive membrane pada proyek A. Hal ini dapat dilihat dari tabel 4.8. Selama 60 hari waktu pengamatan, luas total pekerjaan pemasangan waterproofing jenis self adhesive membrane di proyek A adalah seluas 7981,55 $\mathrm{m}^{2}$. Sedangkan pada pekerjaan waterproofing jenis crystalline di proyek B adalah seluas $8707,5 \mathrm{~m}^{2}$.

\section{KESIMPULAN}

Berdasarkan hasil penelitian studi perbandingan aplikasi self adhesive membrane waterproofing dan crystalline waterproofing serta tingkat efektivitas produktivitas proyek A dan B, maka didapat beberapa kesimpulan yang akan dijelaskan sebagai berikut :

1. Dari hasil pengamatan dapat disimpulkan secara keseluruhan pemasangan waterproofing sesuai dengan SOP dari produsen. Akan tetapi terdapat beberapa perbedaan yang terjadi pada pekerjaan di lapangan yang masih dapat diterima hasilnya.

2. Pada proyek A diperoleh nilai produktivitas rata-rata tenaga kerja adalah sebesar $30,07 \mathrm{~m}^{2} /$ orang-hari, dengan nilai persentase LUR sebesar $88,18 \%$.

3. Pada proyek B diperoleh nilai rata-rata produktivitas tenaga kerja adalah sebesar $40,39 \mathrm{~m}^{2} /$ orang-hari, dengan nilai persentase LUR sebesar 80,23\%.

4. Nilai LUR kedua proyek termasuk dalam kategori efektif dalam penggunaan tenaga kerja (LUR $\geq 50 \%$ ).

5. Nilai produktivitas yang lebih tinggi tidak pasti menunjukkan bahwa suatu pekerjaan berjalan lebih efektif.

6. Semakin banyak pekerja tidak berarti nilai produktivitas pekerjaan semakin tinggi.

\section{DAFTAR PUSTAKA}

Dwi Nurul Izzhati. (2009) Analisis Kinerja Karyawan Dengan Menggunakan Metode Work Sampling (Studi Kasus: Petugas Teknisi Udinus). Artikel Ilmiah Majalah Dian Volume 9 No 1, Universitas Dian Nuswantoro Semarang.

Kaming, P.F., Olomaiye, P.O., Holt, G.D., and Harries, F.C. (1997). Factors Influencing Craftsmen's Productivity in Indonesia. International Journal of Project Management. Vol. 15, No. 1, 21-30.

Oglesby, C. H., Parker H.W. and Howell G.A. (1989). Productivity Improvement in Construction, McGraw-Hill.

Olomolaiye, P.O., Jayawardane, A.K.W. and Harris, F.C. (1998). Construction Productivity Management, McGrawHill, Inc, Singapore.

Pilcher, R. (1992). Principles of Contruction Management 3rd ed, McGraw-Hill, Inc, Singapore.

Richardson, W. J. (1976). Cost Improvement, Work Sampling and Short Interval Scheduling, Reston Publishing Company, Inc., Reston, Va.

Sedarmayanti. 2001. Sumber Daya Manusia Dan Produktivitas Kerja. Bandung: Mandar

Thomas, H. R. (1981). Construction Work Sampling, Construction Management Research Report No. 14, The Business Roundtable, Pennsylvania State Univ., Dept. of Civ. Engrg., University Park, Pa.

Thomas, H.R. (1991). Labor Productivity and Work Sampling: The Bottom Line, Journal of Construction Engineering and Management, 117(3), 